\title{
The strategic and operational landscape of emergency services in the UK
}

\author{
Peter Murphy \\ Nottingham Business School, Nottingham Trent University, Nottingham, UK \\ Paresh Wankhade \\ Edge Hill University, Ormskirk, UK, and \\ Katarzyna Lakoma \\ Nottingham Business School, Nottingham Trent University, Nottingham, UK
}

Received 9 December 2018

\begin{abstract}
Purpose - The organisational and service delivery landscape of the emergency services in the UK has been rapidly changing and is facing further change in the foreseeable future. The purpose of this paper is to examine recent and ongoing organisational changes in the policy development, service delivery and regulatory landscape of the emergency services, in order to capture the overall picture and potential opportunities for improvement or further investigation.

Design/methodology/approach - This general review utilises the characteristics of the three domains of a national framework, namely, policy development, service delivery and public assurance, and uses these characteristics as lenses to examine the three main blue light emergency services of police, fire and ambulances.

Findings - What emerges in the organisational landscape and conceptual maps for the police and even more so for the Fire and Rescue Service, is the immaturity of many of the organisations in the policy and the public assurance domains while the service delivery organisations have remained relatively stable. In the relatively neglected ambulance services, we find the NHS's recent Ambulance Response Programme has considerable potential to improve parts of all three domains.

Research limitations/implications - The review is limited to the UK and primarily focussed on England. Practical implications - The review identifies opportunities for improvement, potential improvement and further research.

Originality/value - Although the National Audit Office has attempted in the past to provide organisational landscape reviews of individual emergency services, this contemporary comparative review of all three services using a common model is unique. It provides considerable new insights for policy makers, service delivers and regulators.
\end{abstract}

Keywords Emergency services, Accountability transparency and public assurance, Organizational landscape, Police fire and ambulance services, Policy and delivery

Paper type General review

\section{Introduction}

The three "blue light" emergency services, police, fire and ambulance services have been facing unprecedented challenges as the nature, form and pattern of risks and emergencies faced by society continues to increase and change (Wankhade and Weir, 2015; Wankhade and Mackway-Jones, 2015; Murphy and Greenhalgh, 2018). Multiple terrorist attacks, historical and contemporary child abuse scandals, and major fire incidents as varied as the "rapidly developed and aggressive wildfires" at Saddleworth Moor to the Grenfell Tower disaster in London and the explosions in Leicester have all challenged the capacity and increased the pressure on the emergency services in recent months. The effective management of emergency services has never been more important than in today's highpressure cost-conscious public sector.

As can be seen from any number of recent government publications, such as the latest National Framework for Fire and Rescue Services (Home Office, 2018a), the government's

Emergency services in the UK 
policies and its response to prolonged austerity in the UK continues to dominate public service delivery, service deployment and the public services regulatory framework. It is, therefore, an obvious starting point to examine the government's policy response to austerity as it affects the emergency services.

In practice, this policy response has two major parameters: the first is the resource package available to the services, and the second is the legislative basis upon which they can act and spend. However, before we examine these two major parameters, it is helpful to illustrate how these two parameters relate to the strategic and operational organisation landscape of emergency services and how all three relate to the three inter-related domains of policy development, service delivery and the regulatory environment designed to provide assurance to the public, the government and the sectors key stakeholders.

We have tried to show all of these relationships on the simple illustrative model next.

The starting point for the development of any public service model must be the public interest and the values and/or principles enshrined within public service. In the UK, this is relatively simple to identify since anyone who works as a public office-holder or a direct or indirect employee in the UK must adhere to the seven principles of public life known as the "Nolan principles" (Committee on Standards in Public Life, 1995). These cover selflessness, integrity, objectivity, accountability, openness, honesty and leadership. They are defined in Table I and shown in Figure 1 as a large outer circle. In developing any policy developments or frameworks for delivery of Emergency Services, ministerial legislators and officials must adhere to and promote these principles in their work. The principles operate across and throughout any public activity, and across and throughout any public service context in the UK. They are not unique to the UK, but are universal to UK public services.

In addition to these values and principles, there are also situational or contextual constraints that act as the strategic parameters to the development of frameworks and other policy/service/assurance regimes. Most national policy documents and frameworks attempt to cover these situational issues at the start of the documents as they "set the scene" for any proposals that follow in the main body of the policy or framework. They generally include the legislative basis that provides the authority and legitimacy for the proposals, the current or revised strategic and operational organisational landscape that the service operates within, the resource envelope deemed to be available and the timescales (short-, medium- and long-term) that the framework is expected to cover.

\section{Standard Description}

1. Selflessness Holders of public office should act solely in terms of the public interest

2. Integrity Holders of public office must avoid placing themselves under any obligation to people or organisations that might try inappropriately to influence them in their work. They should not act or take decisions in order to gain financial or other material benefits for themselves, their family or their friends. They must declare and resolve any interests and relationships

3. Objectivity Holders of public office must act and take decisions impartially, fairly and on merit, using the best evidence and without discrimination or bias

4. Accountability Holders of public office are accountable to the public for their decisions and actions and must submit themselves to the scrutiny necessary to ensure this

5. Openness Holders of public office should act and take decisions in an open and transparent manner. Information should not be withheld from the public unless there are clear and lawful reasons for so doing

6. Honesty Holders of public office should be truthful

7. Leadership Holders of public office should exhibit these principles in their own behaviour. They should actively promote and robustly support the principles and be willing to challenge poor behaviour wherever it occurs

Table I.

Source: Committee on Standards in Public Life (1995, p. 1) 


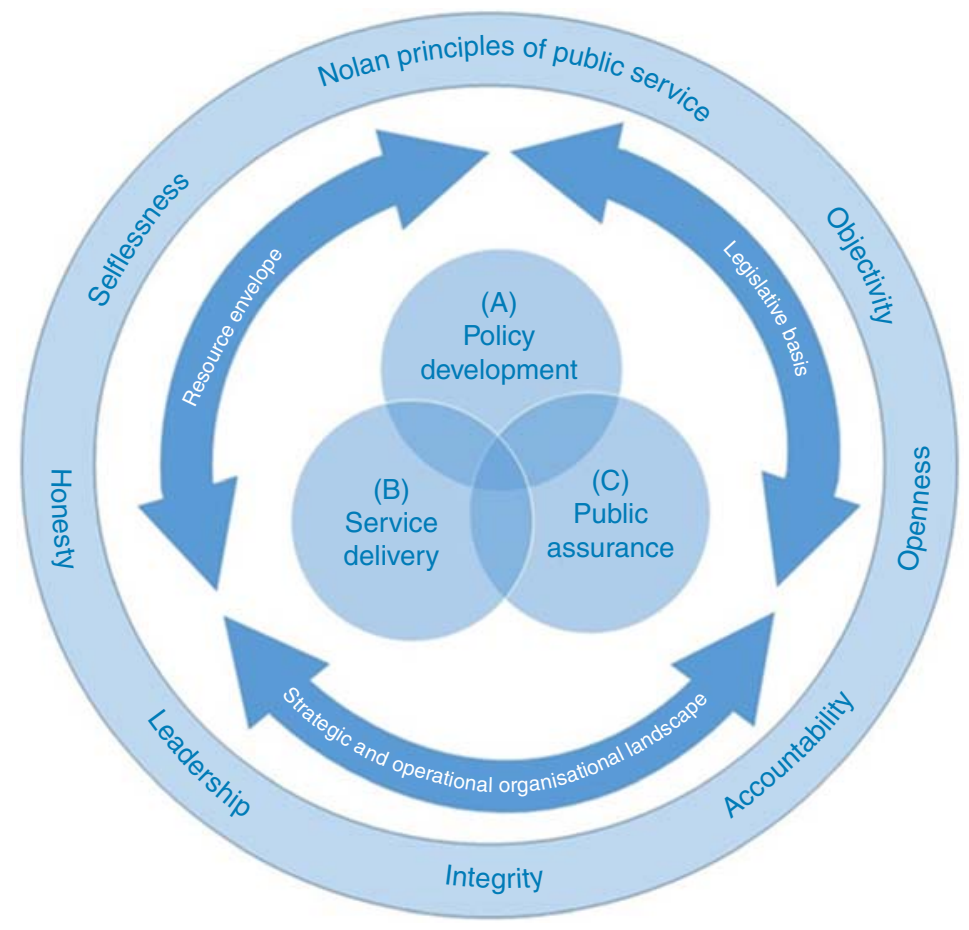

Source: Murphy and Lakoma (2018)
Emergency services in the UK
Figure 1.

Three domains of the organisational landscape

The key components of the context for emergency services in terms of policy/service delivery/public assurance are shown in the second circle.

Since the introduction of National Frameworks for Fire and Rescue Services, the publication of various mission statements and visions for policing services the government's operating mandate for the NHS, it has become apparent that in order to be effective, they need to be cognisant and make provision for three inter-connected "domains". These three domains are shown at the conceptual core of our model. They are:

(1) The policy development domain - which determines the objectives of any policy, whether national, regional or local, but also identifies what the parameters to its development and implementation are, and whether its delivery is feasible and realistic?

(2) The service delivery domain - which determines how the service is to be delivered and ideally how is its delivery is to be optimised, continually improved, sustained, innovated and constructively monitored?

(3) Finally, the assurance or regulatory domain - how is the public to be provided with reassurance that the money taken from them to finance the policy prescriptions and the strategic and operational delivery of the service, is justified and does it provide value for money?

Joined-up policy development (and preferably policy making) is particularly important in services, such as the emergency services, which have mutually inter-dependent responsibilities to the public at national and local community levels (Kozuch and Sienkiewicz-Malyjurek, 2014; Sienkiewicz-Malyjurek, 2017). Efficient and effective service 
delivery in emergency services is also equally inter-dependent at local and national levels. The objectives of the assurance and regulatory arrangements need to transcend all three emergency services to address wider community or public goals and objectives, such as public safety and security, rather than narrow individual organisational goals and objectives.

These three inter-connected domains clearly have overlaps and some of their individual aspects in common. They also have some aspects that are specific to the particular domain. We have illustrated this in Figure 2.

In our model these three core domains also inter-relate with the three broader parameters shown in the first circle, so before we examine the organisational landscapes of the individual emergency services, let us look briefly at both the overall resource envelope and the legislative basis, and the outlook for these two parameters in the UK in the immediate future.

\section{The resource envelope}

On 19 February 2016, the government published 17 single departmental plans for each government department for the period 2015-2020 (Home Office, 2016c). These new plans described the new minority governments objectives and were intended to ensure that each department's plan reflected the policies and priorities of the whole of government and that they could be delivered within the budgets agreed at the Spending Review 2015 (HM Treasury, 2015). At this time, the police were the responsibility of the Home Office, Ambulances and the NHS were the responsibility of the Department of Health, and Fire and Rescue Services were the responsibility of the Department of Communities and Local Government (DCLG). The relevant departmental expenditure limits are given (in cash terms and in billions) in Table II. They effectively represent a medium-term reduction in cash terms and a greater reduction in real terms for all emergency services in all parts of the country.

Although these departmental plans were updated in December 2017 (by which time responsibility for Fire and Rescue Services had been transferred to the Home Office), the latest annual "supply" estimates presented to the House of Commons by Her Majesty's Treasury in April 2017 and April 2018 are still based upon the 2015 Spending Review.

Figure 2.

Components of the three domains
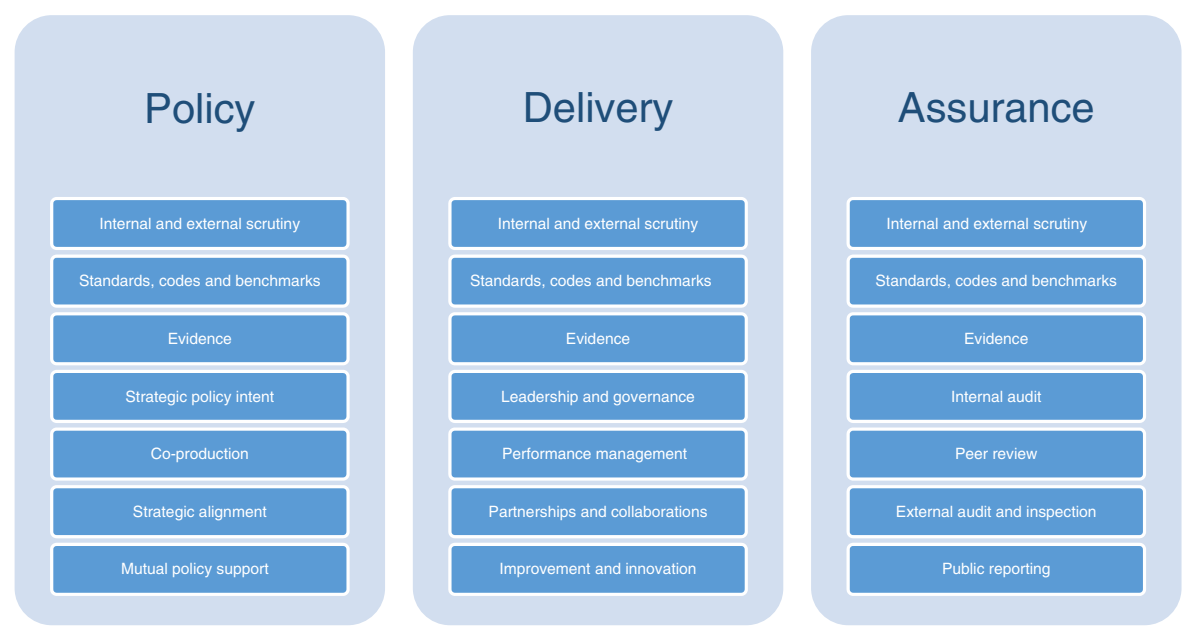

Source: Murphy and Lakoma (2018) 
In fact, the Chancellor Phillip Hammond in his "Spring Statement" in March 2018 (HM Treasury, 2018) made no new spending announcements and stated that the next comprehensive Spending Review to accompany a medium-term financial strategy will not be until 2019. Thus, the "resource envelope" available to all three emergency services and to all three devolved administrations will continue to contract up until 2020/2021.

\section{The legislative framework}

The recent policy response, and the capacity of the government and the civil service to affect statutory change in the UK's legislative framework has been severely curtailed by the need of UK politicians, senior civil servants and policy makers to respond to the challenges of the European Referendum's vote to leave the European Union (EU). The Queen's Speech at the 2017 state opening of parliament (and the legislative programme that followed) was overwhelmingly dominated by the "government's priority to secure the best possible deal as the country leaves the European Union governments" (Cabinet Office, 2017, p. 1). In June 2018, the Prime Minister went two steps further: both cancelling the 2018 Queen's speech to give the government more time to push through laws relating to the exit and doubling the next parliamentary session to two years rather than one to give "MPs and peers the maximum time possible to scrutinise Brexit legislation” (Press Association 2017, p. 1).

Thus, change in the legislative basis in the foreseeable future is likely to be limited. In stark contrast, however, one of the final pieces of major legislation that was enacted immediately before the European referendum dominated the legislative programme did significantly affect and continues to affect the strategic and operational landscape of the emergency services.

This was the Policing and Crime Act 2017, which is a bit of a misnomer of a title since Part 1 of the Act is intended to promote greater strategic and operational collaboration between all three emergency services, and chapters 2-4 deal specifically with Fire and Rescue functions. The Act arguably also generated as many changes in the strategic and operational landscape of Fire and Rescue Services as it did for the police, although it did not have as much impact on the ambulance services as envisioned in the government's original proposals contained in the consultation "Enabling closer working between the Emergency Services" (Home Office, 2016a).

The Policing and Crime Act 2017 is, therefore, a convenient and appropriate place to start to distinguish the strategic and operational landscape of the three individual emergency services. Its antecedence and development straddled the EU referendum and the snap general election announced in April 2017. This resulted in a conservative minority government, supported on a confidence and supply basis by the ten Democratic Unionist MPs from Northern Ireland. It took office on 8 June 2017.

The precariousness of the government's power basis partially explains the difficulties and limitations of the ongoing legislative programme referred to above, as well as the lack of

\begin{tabular}{|c|c|c|c|c|c|c|c|}
\hline $\begin{array}{l}\text { Departmental } \\
\text { expenditure limit }\end{array}$ & 2015-2016 & $2016-2017$ & $2017-2018$ & $2018-2019$ & $2019-2020$ & $2020-2021$ & $\begin{array}{c}\text { Cumulative real } \\
\text { growth }(\%)\end{array}$ \\
\hline Home Office & 10.3 & 10.7 & 10.6 & 10.6 & 10.6 & $*$ & -4.8 \\
\hline $\begin{array}{l}\text { Department of Health } \\
\text { DCLG Local }\end{array}$ & 111.6 & 115.6 & 118.7 & 121.3 & 124.1 & 128.2 & +3.3 \\
\hline Government & 11.5 & 9.6 & 7.4 & 6.1 & 5.4 & $*$ & -6.7 \\
\hline Scotland & 25.9 & 26.1 & 26.3 & 26.3 & 26.5 & $*$ & -5.0 \\
\hline Wales & 12.9 & 13.0 & 13.1 & 13.2 & 13.3 & $*$ & -4.5 \\
\hline Northern Ireland & 9.7 & 9.8 & 9.9 & 9.9 & 9.9 & $*$ & -5.0 \\
\hline
\end{tabular}

Note: *Denotes that the figures are not yet available

Source: HM Treasury (2015)
Emergency

services in the UK 
further changes to the structural and organisational landscapes of public services in England generally, and not merely in the emergency services. There has been no further significant primary legislation, other than economic policy and Brexit-related legislation since the 2017 election. Even then, as can be seen from the updated departmental plans and the latest annual treasury "supply" estimates referred to above, in practice, there has also been no fundamental review of economic policy since this time.

This paper is organised as follows. The next sections will look at recent changes in the organisational landscape of the three individual emergency services. We will begin with the police as the largest service and the service that was the focus of the earliest reforms. Although the activity of Ambulance Services and their organisations are much larger than Fire and Rescue Services, it is helpful to consider Fire and Rescue Services after the police because the government has modelled their reforms of Fire and Rescue Services on previous police reforms. Ambulance Services then provide us with an altogether different perspective as the services themselves have remained relatively unscathed while the organisational landscape around them has been changing rapidly.

\section{Police services}

The police in the UK are an amalgam of "territorial" or locally based services and more specialised forces. The latter have responsibility for more complex and serious levels of crime and predominantly operate on a national basis. This section is concerned with the organisational landscape of the territorial police forces that are controlled locally and deal with the vast majority of crimes, such as robbery, burglary, arson and assault.

The most fundamental changes to the organisation of the territorial police services were not occasioned by the Policing and Crime Act 2017 itself, but by the series of changes instigated by Theresa May when she became Home Secretary in May 2010, under the conservative and liberal democrat coalition government of 2010-2015.

\section{The introduction of police and crime commissioners}

The introduction of police and crime commissioners (PCCs) represented a significant change to the governance of policing in England and Wales as it introduced more direct democratic accountability to the determination of local policing priorities. A directly elected individual replaced the former police authorities and provided a supposedly visible and accountable focus for local policing priorities, local policy debate and collaborative delivery of services.

The Coalition Government published a consultation in 2010 entitled "Policing in the 21st Century" (Home Office, 2010), which represented their future vision for policing, and included the introduction of PCCs as its central idea. This was quickly followed by the introduction of the Police Reform and Social Responsibility Bill in December 2010 and the Police Reform and Social Responsibility Act in 2011. The first elections for PCCs were held in November 2012, and the new commissioners took office on 22 November 2012.

Under the 2011 Act, the core functions of PCCs are to:

- secure the maintenance of an efficient and effective police force within their area; and

- to hold the chief constable to account for the delivery of the police and crime plan.

PCCs are also charged with holding the police finances and assets and raising the local policing precept from council tax and are required to produce an annual report to the public on progress in policing. There is little evidence from the Spending Review (HM Treasury, 2015) or the Home Office (2016a, b) single departmental plans that the introduction of PCCs have impacted on the aggregate level of funding available to the police services or influenced its macro-economic policies. 
However, none of these are any different to the previous responsibilities of the police authorities, although PCCs did become responsible for the appointment, suspension and dismissal of the chief constable, which was the media's initial focus of their post-election activity.

There was however considerable scepticism and disquiet about the introduction of PCCs, from both the public, the media, and the wider criminal justice community, not least because of the speed of introduction and the "lack of evidence" to support the politicians' claims (Murphy et al., 2018). Lister and Rowe (2015) suggest that together with high levels of public confusion and disinterest, this scepticism culminated in turnouts of less than 15 per cent for the first PCC elections in 2012.

By November 2013, the Independent Police Commission (IPC, 2013), established by the Home Secretary Theresa May under the former Chief Commissioner of the Metropolitan Police Lord Stevens, was already suggesting that there needed to be greater attention on the "social justice model of policing" with greater focus on preventing crime, harm and disorder, and greater emphasis on neighbourhood policing as a core commitment of all PCCs. Stevens considered the PCC model to be "flawed" and called for its replacement, although this view was quickly dismissed by the politicians of all parties.

Whilst the governance of the police in England and Wales undoubtedly changed, the amount of change in the organisational landscape of police service delivery looks less radical and remains open to debate. London and the Metropolitan Police, Scotland and Northern Ireland were not affected by these governance changes, there were no amalgamations of police forces or boundary changes and no new front-line "service delivery" organisations were created, other than the National Crime Agency which replaced the Serious Organised Crime Agency and absorbed the Child Exploitation and Online Protection Centre.

It was not the 2011 Act that dealt with the extension of police powers, police complaints, discipline and inspection, and cross-border and inter-service collaboration. These were the subject of the Policing and Crime Act 2017. However, before examining the changes to the public assurance domain, let us turn to changes in the organisational landscape of the policy development domain.

\section{The policy domain}

The organisational landscape of policy making for the police is one of the more straightforward and least complex landscapes in the UK. This was the case prior to the post-2010 reforms and the landscape, in our view, remains relatively simple, if a little more complicated after May's reforms.

This is partially because the police are ultimately the responsibility of the Home Office, and the Home Office, by virtue of its range of responsibilities and historical modus operandi, is still one of the most top-down, centralised and prescriptive policy making regimes in government today. It is not difficult to imagine how policy making for National Security, Immigration and Counter Terrorism could be this way, but, as we will explain later, these tendencies are evident throughout Home Office policy making including local and neighbourhood policing. The activities of Mrs May's "fiercely loyal" and "over-exuberant" special advisors and her inner policy circle within the Home Office set the tone for her later government (Warrell et al., 2017). This narrow and exclusive approach to policy making is still evident in the latest public consultations from the Home Office and its non-departmental public bodies, on local policing and its formal monitoring arrangements (Home Office, 2017; HMICFRS, 2018).

Prior to 2010, policy development and responsibility for local policing was overseen by socalled national "tripartite" arrangements. This trio consisted of the Home Office, the Association of Chief Police Officers (ACPO) and the Association of Police Authorities (APA), the latter being the collective body representing the views of the police authorities. Although clearly not a trinity 
of equals, the three parties met formally and regularly, and this collective approach reflected the joined-up policy and delivery ethos of the New Labour administrations.

The triumvirate was advised on more specialist matters by related bodies such as the Her Majesty's Inspectorate of Constabulary (HMIC), the National Policing Improvement Agency (NPIA) or the Audit Commission, or on workforce matters by representative bodies, such as the Police Federation. These were all replaced or reformed in the new arrangements.

The Home Office has recently reverted to a more dominant position with a top-down, much more prescriptive approach to policy making. The APA and the ACPO have been reformed and the influence of their successors, the Association of PCCs and the National Police Chiefs Council, greatly reduced by statute and circumstances (Murphy et al., 2017). The NPIA has been superseded by the College of Policing and HMIC reformed into Her Majesty's Inspectorate of Constabulary and Fire \& Rescue Services (HMICFRS), both with their influence generally reduced.

\section{Public assurance and regulation}

In 2014, the National Audit Office (NAO, 2014) was already concerned that the complex and changing organisational landscape of policing together with the changing accountability and transparency arrangements, were leading to concerns about the assurance of value for money in police services (NAO, 2015b). This was before the latest series of organisational changes.

The most significant organisations in the public assurance arrangements for policing have, for many years, been HMIC, in terms of operational performance, and the external auditors in terms of fiduciary responsibilities and value for money.

HMIC was established in 1856. Its first 150 years have been recorded by Cowley and Todd (2006) as, in the words of Sir Ronnie Flanagan, the Chief Inspector, "an organisation conceived to ensure the wise spending of exchequer grants by police forces became a catalyst for change and reform, the guardian of professional standards and the credible conscience of the Police Service in England, Wales and Northern Ireland” (p. 1).

This was immediately before HMIC were modernised into an "inspectorate for improvement" under the New Labour administrations (Office of Public Services Reform, 2003), although they later escaped being amalgamated with Her Majesty's Inspector of Courts, Her Majesty's Inspector of Prisons and Her Majesty's Inspector of Probation during Labours proposals for creating four super inspectorates in Education, Health and Social Care, Local Government and Criminal Justice (Thompson, 2005).

In 2013 the Stevens report (IPC, 2013) recommended the abolition of HMIC and the Independent Police Complaints Commission in favour of a new body to oversee standards and complaints and rumours abounded about its possible inclusion in a cull of non-departmental public bodies that subsequently became known (erroneously) as the "bonfire of the quango's" (The Guardian, 2012).

The fact that HMIC escaped was largely due to the appointment of a new chief inspector and HMIC board. Winsor (2011, 2012), previously the rail regulator, had produced his reports on police pay and terms of conditions with a series of recommendations that the government was happy to implement. He was appointed the chief inspector with a new board drawn from a much wider regulatory and inspectorate background, than just ex-policemen.

Instead of abolishing HMIC, Mrs May increased its budget to fund a new programme of force inspections under a new "Performance, Efficiency, Effectiveness and Legitimacy" framework (HMIC, 2017). This programme had a striking resemblance to former Audit Commission programmes and HMIC have subsequently provided regular assessments of organisational performance, as well as thematic and more specialist inspections of services and individual incidents. The nature and form of HMIC operations has since gradually widened in scope and in terms of the organisations that fell under its remit (Murphy et al., 2018). 
Although Mrs May likes to portray herself as a hands-off and light touch sponsor or overseer of police performance and activity (BBC, 2013), in practice, she effectively sought to micromanage the service through the HMIC and other regulators.

The second long-term pillar of external assurance to both the public and the government was the external audit of the service. As mentioned above, this was becoming of concern to the NAO not least because of the narrowing of the scope and content of the audit brought about by the 2014 Local Audit and Accountability Act and its new procedures for local auditing by lightly regulated private auditors that the individual services are now allowed to appoint. The organisational landscape of external audit is now a patchwork quilt dominated by the five largest auditing firms.

The part of the organisational landscape relating to police standards, police conduct and investigation of complaints against the police has also undergone significant change.

All complaints against the police are internally investigated via internal arrangements. An internal Professional Standards Department upholds and promotes the standards of professional behaviour in the force and the standards are set out in a Code of Ethics. The internal systems escalate the most serious complaints to an external national system. There is also a provision for the most serious complaints to be referred directly to either external system.

In historical terms, the first Police Complaints Board was established in 1977 following a series of scandals in the Metropolitan Police. The Board was succeeded by the Police Complaints Authority (PCA) in 1985, a system in which all complaints against the police were investigated by other police officers. As there was not a single prosecution or disciplinary findings against the police during the PCA's existence, the Independent Police Complaints Commission was established in 2004. This demonstrably more effective organisation in its early years was later criticised for the length of its investigations, and in particular the fatal shooting of Mark Duggan, by the police in Tottenham, north London, which sparked the 2011 riots. It was rebranded and reformed into the Independent Office of Police Complaints (IOPC) in January 2018, although like its predecessor, it is a nondepartmental body of the Home Office.

The reforms included slightly wider powers for the IOPC to initiate its own investigations rather than waiting for referrals from forces and the replacement of a panel of commissioners by a Director General.

One further aspect of the assurance domain, which we have referred to in passing and which, to an extent, had been assumed by ACPO, was the establishment of police standards. This responsibility was transferred to the new College of Policing with the specific objective of establishing a Code of Policing Principles and Standards of Professional Behaviour as part of its aims.

The final part of the assurance changes was the establishment of a single repository of data and information on which the government and public could base any evaluation of the performance of the service. This data and information would previously have included the Home Office official crime statistics, the HMIC and Audit Commission reports, individual police authority reports, and self-assessments from the NPIA or the LGA's Improvement and Development Agency, and more specialised reports and investigations on individual subjects or incidents.

A new single website, www.police.uk, was therefore established in 2011, allegedly to enable the public to see crime levels in their area, and the action being taken by the police and criminal justice agencies. As a glance at its site map will show, it is actually primarily a signposting service to police services with virtually no evaluative or critical information.

\section{Fire and rescue services}

Between the turn of the century and 2010, Fire and Rescue Services in the UK experienced unprecedented reform with the introduction of new performance management 
arrangements and service modernisation, greater emphasis on prevention and protection, and the rise of the Audit Commission as the principal regulator. Co-production and collective responsibility for policy and service delivery were enshrined in successive National Frameworks in England (ODPM, 2004, 2006; DCLG, 2008), while Scotland and Wales experienced devolution. The need for better collaboration and pressure for greater "blue light" co-operation was enshrined in the 1998 Crime and Disorder Act, which introduced Community Safety Partnerships, the Civil Contingencies and the Fire and Rescue Services Acts of 2004, and the introduction of Local Area Agreements in the Local Government and Public Involvement in Health Act 2017. All this radically changed both the modus operandi and the organisational landscape of Fire and Rescue Services in the UK (Raynsford, 2016; Murphy and Greenhalgh, 2018).

This period was however followed by the austerity-localism and cutback management agenda of the Coalition Government (Lowndes and Pratchett, 2012). This manifested itself in a systematic dismantling of the improvement infrastructure and centralised performance management arrangements in favour of "Sector-led improvement", a retreat from evidencebased policy making and the abdication of leadership and management of Fire and Rescue Services by the DCLG under Secretary of State Eric Pickles (Ferry and Murphy, 2015; NAO, 2015a; Murphy and Ferry, 2018).

A new National Framework for Fire and Rescue Services had been published in 2012. It identified a range of "new" or increasing risks and challenges such as climate change, an ageing population and the threat of terrorism, but emphasised the need to reduce spending (DCLG, 2012). There was a shift from co-production and collaborative working across the public sector towards a greater emphasis on individual organisational accountability and accountability to local residents. Accountability moved from central government as responsibility was handed to fire and rescue authorities, giving authorities theoretical freedom and flexibility to deliver services, while, in practice, unremitting spending cuts restricted their ability to act.

By 2015, the inadequacy of this approach had become evident to a government, which had become discontent with the speed of change within the fire sector. It coincided with Mrs May's increasing conviction that the introduction of PCCs had cross-party support and was a potential catalyst for change (Murphy and Greenhalgh, 2018). The conservative manifesto included a suggestion that police and fire should work together and the role of PCCs should be developed.

However, it was two critical reports into accountability and the financial resilience of Fire and Rescue Services from the NAO (2015a, b) and the Public Accounts Committee (2016) of the House of Commons that really "lit the blue touch paper". These criticised the leadership, oversight, and management of the sector by the DCLG. They noted the erosion of the evidence upon which policy and decision making was taking placed and highlighted the lack of an independent external inspectorate.

After the first report in November 2015, the government announced the transfer of responsibility for Fire and Rescue Services back to the Home Office. After the second report, Mrs May announced that she would be accepting all of the recommendations of the PAC report and including additional amendments in the Policing and Crime Bill then at its third reading stage in the House of Commons (Home Office, 2016b). Thus, chapters 1 to 4 of the Policing and Crime Act 2017, are some of the most radical potential changes in the organisational landscape of Fire and Rescue Services, but Fire or Rescue does not feature in its title.

\section{The policy domain}

While it may be early days, the new policy making approach and organisational landscape for Fire and Rescue Services at the national level under the Home Office looks remarkably familiar to that of the police. 
Publishing the new national framework between Christmas and the New Year with little publicity does not suggest the Home Office is looking for open consensual evidence-based policy development still less joined-up policy making or collaborative delivery. The minimum six weeks statutory consultation process closed in February.

The government's response to the 70 representations made to the consultation (Home Office, 2018b) was published on the 8th May, the same day that the final framework was published (Home Office, 2018a). The new framework came into effect on the 1st June 2018. The policy appears to be almost exclusively driven by civil servants, minister's special advisors and their political masters, with little discussion or engagement with third parties. It is not even clear from the government's response to representations how much influence even key stakeholders such as the NFCC (National Fire Chiefs Council) or the Association of Police \& Crime Commissioner or the LGA have had on the framework.

The whole process and all consultation responses came from the Fire and Rescue Sector and PCCs. Improving fire safety to the public, at either national or local levels, involves multiple services or sectors and policy programmes should preferably be aligned and mutually reinforcing, as demonstrated by the Grenfell disaster.

It is too early to see how the policy development process will operate under Police Fire and Crime Commissioners, but Mrs May, when introducing the new arrangements criticised the poor and deteriorating evidence base available to policy makers and service deliverers (Home Office, 2016b). Evidence-based policy development has been a characteristic of Fire and Rescue Services throughout its history. Adequately assured, high-quality data is vital to this process. Effective tools, systems, and processes to capture, interrogate and interpret data, make it accessible to policy developers, service deliverers, and intelligible to the public are just as essential to national and local policy making as it is in the service delivery and assurance domains.

The first report from Dame Judith Hackitt's investigation (Hackitt, 2017) into the fire regulations suggests the current evidence base is insufficient for the task. In that case, it has already been found to be partial, contradictory, and no longer fit for purpose. The evidence base for the latest national framework is in our view neither comprehensive nor compelling.

Whilst a new central body for standards, codes, and regulations is one part of the government's new sector infrastructure, as well as a new dedicated website (similar to www.police.uk), both of these initiatives, are at best, in the early stages of development. HMICFRS may contribute to this evidence in the future, however in comparison to the research and intelligence provided by the former Audit Commission, the former Improvement \& Development Agency and its Knowledge Exchange, the Local Government Leadership Centre, the former Fire Inspectorate, and/or the Fire Service College, it is not very reassuring.

\section{Service delivery}

The governance and management of Fire and Rescue Services in England and Wales is likely to take a number of different forms as a result of the Policing and Crime Act 2017.

Since devolution, Scotland has developed a single national service responsible to the devolved government. Northern Ireland has had a single service governed by a board since 2006. London Fire Brigade has had an elected mayor and bespoke policy and scrutiny arrangements for some time, although statutory responsibility for the running of the brigade now lies with the London Fire Commissioner, who replaced the London Fire and Emergency Planning Authority in April 2018. Manchester is following a similar path and other core cities such as Liverpool and Birmingham who have recently elected Mayors are investigating this among other options.

In the remainder of England and Wales, there is now discretion to transfer the governance of Fire and Rescue Services to the PCC, who would become the Police, Fire and 
Crime Commissioner (PFCC), either as a governing body or as a direct employer of all staff. This is subject to an appropriate "local case" being made by the PCC to the Home Secretary. It applies to existing single authority, combined authority, and metropolitan authority Fire and Rescue Services. As this process is discretionary, and the Home Office has to date received eight local cases, it is reasonable to assume that some existing fire and rescue authorities will remain in the foreseeable future although the direction is clearly towards more PFCCs in the future.

As a result of Chapter 1 of the Policing and Crime Act 2017, all emergency services are actively investigating joint or collaborative delivery of a greater range of their services or activities. Although all regional ambulance services are actively engaged in at least some of these initiatives, the vast majority of activity has been in police and fire services with backoffice support and estates initiatives currently the most numerous. Combined control centres have also figured prominently. As a result of previous legislation, fire and rescue authorities can outsource parts or all of their services to private or voluntary sector providers, although this has had to-date limited impact.

One other consequence has been the loss of momentum towards combining fire and rescue authorities and services into larger service units, which was encouraged on a voluntary basis by previous Labour, Conservative and Coalition Governments but has made very slow progress in England and Wales in the past 30 years. It is interesting to speculate as to whether the new governance arrangements will make amalgamations more or less likely in the future, although the economies of scale, organisational efficiencies, and consequent resilience of the larger services suggest pressures to amalgamate will not disappear.

The organisational landscape for the delivery of Fire and Rescue Services therefore appears paradoxical. There are unlikely to be significant changes in the overall number of core service delivery organisations but the nature, scope, structure, governance, and disposition of the services they provide are going to diversify considerably.

\section{Public assurance and regulation}

Concerns about the deteriorating public assurance arrangements and in particular whether the risks to fire and services achieving value for money in a period of diminishing resources from the central government were at the heart of the NAO (2015a, b) and Public Accounts Committee (2016) reports. The basis for these concerns has been articulated elsewhere (Murphy and Greenhalgh, 2018; Murphy et al., 2018), and it is the response to these reports and in particular the changes to the organisational landscape of public assurance surrounding Fire and Rescue Services, which concerns us in this paper.

In May 2018, the government announced that a Fire Standards Board will be created to ensure standards are nationally coordinated to a high level across the sector. The proposal had been developed with the NFCC, the Local Government Association and other partners following the NAO and PAC reports. The organisation will have a governing board which will be independent of the government, and the NFCC will produce the standards, drawing on external expertise as they see fit.

In addition, as mentioned above a new central data repository with a dedicated website available to the public, will be created. This will be similar to the police website but is in the very early stages of design and development.

The most significant development was to be the creation of a new rigorous and independent inspection regime delivered by a new external inspectorate. In the event, the new inspectorate emerged as an extended and rebranded HMIC, which has been renamed HMICFRS, with the same board as its predecessor reporting annually to the Home Secretary who would also have the power to direct inspections.

Ideally, a truly independent external inspectorate and chief inspector would be focussed on the publics' interest and public disclosure. They would design and implement, hopefully 
in collaboration with the government and the services, a robust, comprehensive, risk-based and proportionate inspection programme. Rather than reporting to the government they should have independent reporting rights and responsibilities.

However, following the Home Office example, HMICFRS (2017) issued a consultation document on its proposed inspection regime in the week before Christmas 2017, with a statutory consultation that closed in February 2018. The final regime and first years programme were issued in the week before Easter on 29th March 2018 (HMICFRS, 2018). The first pilot inspections are being implemented and it is not the purpose of this chapter to evaluate individual organisations. Suffice to say, HMICFRS is clearly the single most significant addition to the public assurance landscape of Fire and Rescue Services and their strategic and operational positioning as well as their performance is crucial to the sector's improvement.

It will also be interesting to see the nature and development of the relationship between the emerging HMICFRS regime and the other key assurance regime, namely, the financial assurance arrangements. As mentioned in relation to the police, external audit arrangements have weakened and become less transparent in recent years with an increasing reliance on so-called Armchair Auditors (Home Office, 2017). This partially results from the loss of the Audit Commission, from the narrowing of the scope and content of the external audit in the Local Audit and Accountability Act 2014, and from clearly inadequate public reporting requirements.

\section{Ambulance services}

The history of organisational change in ambulance services themselves is conceptually relatively simple in terms of two aspects: the nature of the services provided and the organisations that provide the services.

Ambulance services have gone from an emergency service that sought to get patients to clinical or medical treatment as quickly and efficiently as possible, to a service providing a range of pre-hospital urgent and planned healthcare services for people who often have serious or life-threatening conditions (Pollock, 2013; Wankhade, 2011). The modern ambulance has one of the most important concentrations of sophisticated medical and clinical equipment (and human resources) in the NHS. However, this change is not the primary focus of this paper.

\section{Service delivery}

The history of NHS Ambulance Service organisations in the UK, which is our focus, is one of relentless rationalisation and increasing size in terms of individual organisations providing core services, supplemented by a slowly declining, but extremely valuable voluntary and charitable sector operating in close collaboration with the NHS. In recent years, this has been complicated at the margins by the privatisation of some non-emergency transport services, a process exacerbated by the implementation of the Health and Social Care Act 2012.

The National Health Service Act 1946 gave councils in England and Wales a statutory responsibility to provide an emergency ambulance service, although they could contract this to a voluntary service. The service remained a local authority responsibility until 1974 when the 142 ambulance services in England and Wales were transferred to central government control by the National Health Service Reorganisation Act 1973 and consolidated into 53 services under regional or area health authorities.

As a result of the National Health Service and Community Care Act 1990, England was covered by 31 ambulance trusts, which were re-structured again in 2006. By then, the system comprised 14 NHS organisations, 11 of which were trusts covering the regions of England with single services for Scotland, Wales and Northern Ireland, respectively. This remains the case today. The Health and Social Care Act 2012 was the biggest top-down 
reorganisation of the NHS in its history. It radically changed the organisational landscape, in which Ambulance Services are obliged to operate, but the only change it made to the ten Ambulance Trusts in England, was to make them Foundation Trusts. The Association of Ambulance Chief Executives acts as a central organisation for the ambulance services in providing support and coordinating national policy while also acting as a central resource for information about NHS ambulance services.

Although ambulance services are not complicated organisations per se after the 2012 Act, they have subsequently had to operate in an NHS organisational landscape and operating environment, which has become more complex and makes it extremely difficult to manage their operations and their finances.

Ambulances and ambulance services have very little control over the demand for their services, they go wherever the need arises or an incident happens. They also have very little influence over the next step in the process - the supply or capacity of hospitals to accept patients, with the unwanted consequence that increasing turnaround times at hospitals have entered the nation's consciousness.

The changes to the Health and Social Care organisational landscape was so complicated that, in 2012, the Department of Health produced 19 factsheets to try and explain the changes. These factsheets included a health and care structures factsheet, a clinically-led commissioning factsheet, and a greater accountability, locally and national factsheet (Department of Health and Social Care, 2012). These give some idea of the extent of change in the organisation and system surrounding ambulance trusts, while the provider regulation factsheet explains the role of foundation trusts. In effect, both the commissioning and the provider landscapes became more complicated at local, regional and national levels, as more rather than fewer organisations were created. Operationally it was also made more difficult as key systemic responsibilities were replaced by much looser and less effective arrangements. For example, the former strategic health authorities and primary care trusts had specific obligations to coordinate and oversee the collective provision of NHS services by local delivery organisations in defined local areas, both strategically and operationally.

Since the 2012 Act was implemented, there has been widespread and increasing public and government acceptance that ambulance services have been under extreme and unrelenting pressure, reinforced by extensive media coverage over the inability to admit patients quickly and efficiently to Accident and Emergency Departments (A\&E) up and down the country. This results from the inexorable increase in the number of admissions to A\&E, exacerbated every year by winter illnesses and poor living conditions, known as "winter pressures" (Wankhade, 2018; Public Accounts Committee, 2017).

The NAO (2017) recently confirmed that this problem is now nationwide, likely to continue and is unlikely to be resolved by short-term fixes or one-off injections of short-term resources. In these circumstances, the government's response has often been structural reform, if only to distract criticism from government and respond to inevitable calls for the government to "do something".

Further structural reform of ambulance services would clearly have been counterproductive and as mentioned above, the proposed governance and operational changes for Ambulance Services suggested in the consultation "Enabling closer working between the Emergency Services" (Home Office, 2016a) were quietly dropped from the subsequent Policing and Crime Act 2017.

The only proposals that survived the scrutiny and consultation processes were the provisions for greater emergency service collaboration in Part 1 Chapter of the Act, designed to improve the efficiency and effectiveness of police forces, through greater collaboration with the other emergency services. It makes no claim to improve the efficiency and effectiveness of ambulance services and "ambulances" or "ambulance services" are mentioned only 11 times in the whole 2017 Act, with all mentions being in Chapter 1. 
The organisational landscape of service delivery for ambulances was made more complicated by the changes brought about by the Health and Social Care Act 2012, and has not been significantly changed since. It remains to be seen whether or how the implementation of Sustainable Transformation Plans or the move to Accountable Care systems (more recently

Emergency services in the UK described as Integrated Care systems) will impact ambulance services.

\section{The policy domain}

If the service delivery domain for ambulance services has become more complex and complicated, at least policy making is much more straightforward. At a national level, policy is effectively determined by the government through the Department of Health and NHS England, who between them determine overall policy on commissioning. In the past, they were advised by the Ambulance Services Commissioning Group of the NHS Federation, which effectively consisted of the Ambulance Trusts. Since 2015, the NHS Clinical Commissioners (the independent collective voice of Clinical Commissioning Groups (CCGs)) has taken on the role of hosting the National Ambulance Commissioners Group (later renamed NAC Network). From its origins as an informal forum for the lead ambulance commissioners in England, it has developed into a wider network of commissioning managers and clinical leads from CCGs across the country, with a key interest in ambulance commissioning.

At the local level policy and commissioning is operationalised through a designated lead CCG for the region (NHS Federation, 2012). Previously, at regional and local levels, this would have been influenced by Strategic Health Authorities and the Primary Care Trusts whose role it was to coordinate and oversee the collective provision of NHS services by local delivery organisations in defined local areas. This has been replaced with much looser arrangement involving lead CCGs, and was clearly one of the drivers for the creation of the NAC Network.

This apparently relatively simple policy landscape for ambulances has to be caveated and put into context, and that context is the NHS itself. The NHS as a whole is a huge organisation, with an annual operating budget of some $£ 120 \mathrm{bn}$, and around $1.2 \mathrm{~m}$ staff (Department of Health, 2016). Whilst individual ambulance services would amount to medium-sized organisations if they were standalone organisations, they are, in reality, a part of the NHS and when compared to the overall scale of NHS activities and services, their needs can be easily overlooked and underappreciated.

Within the NHS, they find it extremely difficult to compete for influence with the big beasts of the general or acute hospitals, or the commissioning sectors. Although a grateful public may admire and appreciate the ambulance taking them to hospital, when it comes to priorities, they appear to prefer to support policy initiatives and extra investment in the hospitals or other healthcare environments that subsequently treat them.

Nevertheless, after many years of acknowledging a growing problem, in 2013, NHS England undertook a review of urgent and emergency care with a number of work programmes one of which was the Ambulance Response Programme (ARP).

The ARP included a number of practical initiatives but also included a "full review of ambulance service measures and quality indicators". In September 2015, Sheffield University's School of Health and Related Research was engaged to independently monitor, analyse and evaluate the ARP, and in July 2017, they published their final report (Turner et al., 2017).

The ARP covered over $14 \mathrm{~m}$ calls, testing a new operating model and a new set of targets. The results were so impressive that in the same month as publication, NHS England wrote to Jeremy Hunt recommending that the new model be rolled out across the country by the end of 2017 (Keogh, 2017). By December 2017, a formal government impact assessment confirmed that the ARP "delivers operational efficiency, financial efficiency in terms of cost avoidance and potential improvements to clinical outcomes". It looks as if the new model 
and performance arrangements will be implemented in the near future. These will mean significant internal changes to the nature and deployment of ambulance services, and to their working relationships with other key delivery partners. It is not anticipated that they will result in any changes to the number of ambulance trusts.

The ARP is a clear example of the evidence base for a change in policy also becoming part of the data and monitoring information for future service delivery, and eventually forming part of the public assurance and performance management arrangements for the service. It is, therefore, appropriate to turn our attention to the organisational landscape of the assurance domain that ambulance services operate within.

\section{Public assurance and regulation}

As ambulance services remain part of the NHS, they are part of the largest and most comprehensive information and databases in the world, and the National Institute for Health and Care Excellence (formerly National Institute for Clinical Excellence) provides comprehensive evidence-based standards and guidance. As in the policy domain, their relatively small size can be both a challenge and an opportunity.

The NHS public assurance and regulatory regime is inevitably one of the largest and most complicated in the public services. However, there are a number of key institutional pillars, in terms of service delivery and quality: financial resilience and fiduciary duties, public reporting and collaborative engagement with other key public and private service providers.

The Care Quality Commission $(\mathrm{CQC})$ is the independent regulator of health and adult social care in England. Their purpose is to "make sure health and social care services provide people with safe, effective, compassionate, high-quality care and we encourage care services to improve". They were originally formed from the amalgamation of the Healthcare Commission (formally the Commission for Healthcare Audit and Inspection) and the Commission for Social Care Inspection (2003-2009), although the role and remit has expanded to other areas of provision. The two former commissions were created from previous inspectorates under the new labour modernisation initiative of transforming public inspectorates to focus on "inspection for improvement" (Office of Public Services Reform, 2003).

The subsequent creation of CQC was part of Labour's proposals for creating four super inspectorates in Education, Health and Social Care, Local Government and Criminal Justice (Thompson, 2005). Although CQC has grown to become the largest inspection and regulatory organisation in the UK, there is a bespoke ambulance inspection framework which was last updated in February 2018. It is widely anticipated that this will incorporate changes arising out of the ARP in due course.

One enduring problem for the ambulance services is, however, to keep within the resource envelope of their operating budget set annually by the NHS. This was exemplified by their experience with the previous requirement to achieve Foundation Trust Status. Foundation Trust status was abandoned as a result of the enduring financial crisis in the NHS, which undermined the supposed autonomy and financial resilience of these trusts.

Prior to 2010, NHS trusts were externally audited and monitored by the District Audit and the Audit Commissions through Auditors Local Evaluations. Currently, they are subject to regulation by NHS Improvement which incorporated MONITOR, the regulator of NHS Financial Trusts in 2016. Originally established in 2004, MONITOR was responsible for authorising, monitoring and regulating NHS Foundation Trusts. Ambulance trusts collectively found achieving the financial standards of foundation status particularly difficult and a lower proportion of ambulance trusts achieved foundation status than any other category of NHS service providers. 
This was because, as mentioned above, ambulance services have very little control over the demand for their services and little influence over the supply or capacity of hospitals to accept patients. With demand rising inexorably, hospital bed numbers declined, commissioning budgets squeezed and ambulance trust deficits were inevitable (NAO, 2017; Wankhade, 2018).

As with the Police and Fire Services, public assurance from external audit has weakened and become less transparent as a result of the narrowing of the scope and content of the audit brought about by the 2014 Local Audit and Accountability Act and the current procedures for local auditing by lightly regulated private auditors that individual services are allowed to appoint.

Public reporting engagement and scrutiny has, however, been improved as the Parliamentary and Health Service Ombudsman and the Local Government Ombudsman (for Social Care) have been complemented by the creation of national and local "Healthwatch" established under the 2012 Act as the "independent national champion for people who use health and social care services". These public and patient champions were created as a result of the Mid Staffordshire Hospitals scandals and the reports of persistently poor patient care (HMG, 2013). They comprise a national team supporting a network of approximately 150 local Healthwatch organisations that are largely based on local authority boundaries, although rationalisations and amalgamations are beginning to occur as a result of budget cuts.

\section{Conclusions}

This paper has attempted to do two things to help our understanding of the organisational landscape of the three emergency services.

Conceptually, it has attempted to identify the nature of roles and responsibilities that are involved in the three activities or "domains" as we have labelled them, namely, are policy development, public service delivery and public assurance. It has tried to show how these are related to each other and to wider considerations such as public service values. It has suggested that each of these domains is made up of a subset of concepts and activities, some of which are common to all three domains, and some of which are more specific to a particular domain.

We have then taken that conceptual framework and attempted to map the changing organisational landscape of the three emergency services in terms of the three domains. Although it is not our purpose to evaluate the performance of individual organisations, past or current, we recognise that we may have strayed into subjective or evaluative areas when comparing the current landscape to ones that have existed in the past. Our purpose is to map the overall picture, so that future research can look at the strengths and weaknesses, and perhaps identify potential improvements in the organisational landscape or the conceptual framework.

What emerges in the organisational landscape and conceptual maps for the police and even more so for Fire and Rescue Services, apart from the (over) dominance of the Home Office, and potentially to a lesser extent HMICFRS in the public assurance domain, is the relatively recent development of many of the organisations in the policy and the public assurance domains while the service delivery organisations have remained relatively stable.

In the ambulance services, which appear to have been much neglected in the recent past, in terms of all three domains, the contextual and organisational landscape is dominated by the structures imperatives and institutions of the wider NHS and its policy development, service delivery and public assurance arrangements. Although these are almost continually changing, they appear to be the most comprehensive and robust of the organisational landscapes. However, in the ARP, there finally appears to be an initiative with the potential to have a transformative impact on all three domains within the service. Whether it will do so will, of course, be for others to evaluate in the future. 


\section{References}

BBC (2013), "Police forces facing dozens of new performance targets", BBC News, 19 September, available at: www.bbc.co.uk/news/uk-24148129 (accessed 9 September 2018).

Cabinet Office ( (2017), “Queen's speech 2017”, available at: www.gov.uk/government/speeches/queensspeech-2017 (accessed 7 September 2018).

Committee on Standards in Public Life (1995), "The 7 principles of public life", available at: www.gov. uk/government/publications/the-7-principles-of-public-life (accessed 9 September 2018).

Cowley, R. and Todd, P. (2006), “The history of Her Majesty's inspectorate of constabulary - the first 150 years, 1856-2006", HMIC, London.

DCLG (2008), "Fire and rescue service national framework 2008-11", TSO, London.

DCLG (2012), "Fire and rescue national framework for England", TSO, London.

Department of Health (2016), "Single departmental plans for 2015 to 2020", Dept of Health, available at: www.gov.uk/government/collections/single-departmental-plans-for-2015-to-2020\#singledepartmental-plans-2015-to-2020 (accessed 20 August 2018).

Department of Health and Social Care (2012), "Health and social care act 2012: fact sheets", available at: www.gov.uk/government/publications/health-and-social-care-act-2012-fact-sheets (accessed 7 September 2018).

Ferry, L. and Murphy, P. (2015), "Financial sustainability, accountability and transparency across local public service bodies in England under austerity", Report to National Audit Office (NAO), London.

Hackitt, J. (2017), "Building a safer future: independent review of building regulations and fire safety: interim report", TSO, London.

HMG (2013), "Report of the Mid Staffordshire NHS foundation trust public inquiry vols 1-3 (The Francis reports)", available at: www.gov.uk/government/publications/report-of-the-midstaffordshire-nhs-foundation-trust-public-inquiry (accessed 9 September 2018).

HMIC (2017), "Inspection programme and framework 2017/18”, HMIC, London.

HMICFRS (2017), "Proposed fire and rescue services inspection programme and framework 2018/19 for consultation", HMICFRS, London.

HMICFRS (2018), "Fire and rescue services inspection programme and framework 2018/19", HMICFRS, London.

HM Treasury (2015), “Spending review and autumn statement 2015”, HM Treasury, London.

HM Treasury (2018), "Spring statement 2018”, available at: www.gov.uk/government/speeches/springstatement-2018-philip-hammonds-speech (accessed 7 September 2018).

Home Office (2010), "Policing in the 21st century: reconnecting police and the people", TSO, London.

Home Office (2016a), "Enabling closer working between the emergency services”, TSO, London.

Home Office (2016b), "Home secretary speech on fire reform", available at: www.gov.uk/government/ speeches/home-secretary-speech-on-fire-reform (accessed 7 September 2018).

Home Office (2016c), "Single departmental plans for 2015 to 2020", available at: www.gov.uk/ government/collections/single-departmental-plans-for-2015-to-2020\#single-departmentalplans-2015-to-2020 (accessed 20 August 2018).

Home Office (2017), "Fire Minister's speech to reform", available at: www.gov.uk/government/ speeches/fire-ministers-speech-to-reform (accessed 19 March 2018).

Home Office (2018a), "Fire and rescue national framework for England”, Home Office, London.

Home Office (2018b), "Fire and rescue national framework for England: government response to consultation", Home Office, London.

IPC (2013), "Policing for a better Britain: report of the Independent Police Commission”, The Lord Stevens of Kirkwhelpington QPM, TSO, London. 
Keogh, B. (2017), "Ambulance Response Programme: letter to secretary of state”, NHS England, Leeds, available at: www.england.nhs.uk/wp-content/uploads/2017/07/ambulance-responseprogramme-letter.pdf (accessed 15 August 2018).

Kozuch, B. and Sienkiewicz-Malyjurek, K. (2014), "New requirements for managers of public safety management systems”, Procedia: Social and Behavioural Sciences, Vol. 149 No. 2014, pp. 472-478.

Lister, S. and Rowe, M. (2015), "Electing police and crime commissioners in England and Wales: prospecting for the democratisation of policing", Policing and Society, Vol. 25 No. 4, pp. 358-377.

Lowndes, V. and Pratchett, L. (2012), "Local governance under the coalition government: austerity, localism and the "Big Society", Local Government Studies, Vol. 38 No. 1, pp. 21-40.

Murphy, P. and Ferry, L. (2018), "Another turn of the screw: fire and rescue under the Coalition Government of 2010-2015", in Murphy, P. and Greenhalgh, K. (Eds), Fire and Rescue Services: Leadership and Management Perspectives, Springer, London, pp. 45-59.

Murphy, P. and Greenhalgh, K. (Eds) (2018), Fire and Rescue Services: Leadership and Management Perspectives, Springer, Berlin.

Murphy, P. and Lakoma, K. (2018), "Shifting tectonic plates: changes to the strategic and operational landscape of the emergency services in the UK", Fire Related Research and Developments Conference (RE18), West Midlands Fire \& Rescue Service Headquarters, Birmingham, 13 November, available at: http://irep.ntu.ac.uk/id/eprint/35221/ (accessed 7 December 2018).

Murphy, P., Eckersley, P. and Ferry, L. (2017), “Accountability and transparency: police forces in England and Wales", Public Policy and Administration, Vol. 32 No. 3, pp. 197-213.

Murphy, P., Ferry, L., Glennon, R. and Greenhalgh, K. (2018), Public Service Accountability: Rekindling a Debate, Palgrave Macmillan, Cham.

NAO (2014), "Police accountability: landscape review", NAO, London.

NAO (2015a), "Financial sustainability of fire and rescue services HC 491", NAO, London.

NAO (2015b), "Financial sustainability of police forces in England and Wales", NAO, London.

NAO (2017), "NHS ambulance services", NAO, London.

NHS Federation (2012), "National ambulances commissioning group - integrated ambulance commissioning in the new NHS Briefing Note 252 November 2012", NHS Federation, London.

ODPM (2004), "The fire and rescue service national framework 2004/05", ODPM, Wetherby.

ODPM (2006), “The fire and rescue service national framework 2006/07”, ODPM, London.

Office of Public Services Reform (2003), Inspecting for Improvement: Developing a Customer Focused Approach, Cabinet Office, London.

Pollock, A.C. (2013), "Ambulance services in London and Great Britain from 1860 until today: a glimpse of history gleaned mainly from the pages of contemporary journals", Emergency Medicine Journal, Vol. 30 No. 3, pp. 218-222.

Press Association (2017), "Queen's speech to MPs dropped next year to allow for Brexit laws", The Guardian, 17 June, available at: www.theguardian.com/politics/2017/jun/17/queens-speech-tomps-dropped-next-year-to-allow-for-brexit-laws (accessed 7 September 2018).

Public Accounts Committee (2016), "Financial sustainability of fire and rescue services twenty-third report of session 2015-16", TSO, London.

Public Accounts Committee (2017), "NHS ambulance services: sixty-second report of session 2016-17", Stationery Office, London.

Raynsford, N. (2016), Substance Not Spin: An Insider's View of Success and Failure in Government, Policy Press, Bristol.

Sienkiewicz-Malyjurek, K. (2017), Inter-Organisational Collaboration in the Public Safety Management System, Scholar Publishing House, Warsaw.

The Guardian (2012), "Bonfire of the Quangos: the victims", The Guardian, 22 August, available at: www. theguardian.com/politics/2012/aug/22/bonfire-quangos-victims-list (accessed 7 September 2018). 
Thompson, W. (2005), "Wither inspection public net; the public service community", available at: www. publicnet.co.uk/features/2005/09/02/whither-inspection/ (accessed 9 September 2018).

Turner, J., Jacques, R., Crum, A., Coster, J., Stone, T. and Nicoll, J. (2017), "Ambulance Response Programme: evaluation of phase 1 and phase 2: final report", available at: www.england.nhs.uk/ wp-content/uploads/2017/07/ARPReport_Final.pdf (accessed 7 September 2018).

Wankhade, P. (2011), "Performance measurement and the UK emergency ambulance service: unintended consequences of the ambulance response time targets", International Journal of Public Sector Management, Vol. 24 No. 5, pp. 382-402.

Wankhade, P. (2018), "The crisis in NHS ambulance services in the UK: let's deal with the 'elephants in the room?", Ambulance Today, Vol. 15 No. 1, pp. 13-17.

Wankhade, P. and Mackway-Jones, K. (Eds) (2015), Ambulance Services: Leadership and Management Perspectives, Springer, New York, NY.

Wankhade, P. and Weir, D. (2015), Police Services: Leadership and Management Perspectives, Springer, Berlin.

Warrell, H., Parker, G. and Blitz, J. (2017), "Theresa May reshapes administration in Home Office mould", Financial Times, 26 February, available at: www.ft.com/content/db6dd3c2-f849-11e69516-2d969e0d3b65 (accessed 7 September 2018).

Winsor, T. (2011), "Independent review of police officer and staff remuneration and conditions: part 1: report (Vol. 8024)", TSO, London.

Winsor, T.P. (2012), "Independent review of police officer and staff remuneration and conditions final report (Vol. 8325)", TSO, London.

\section{Further reading}

Home Office (2018c), "Home Office single departmental plan (update 23rd May 2018)", available at: www.gov.uk/government/publications/home-office-single-departmental-plan/home-officesingle-departmental-plan-2 (accessed 9 September 2018).

NAO (2015c), "Local government variation in spending by fire and rescue authorities 2011-12 to 2013-14", $\mathrm{NAO}$, London.

\section{Corresponding author}

Peter Murphy can be contacted at: peter.murphy@ntu.ac.uk

For instructions on how to order reprints of this article, please visit our website: 